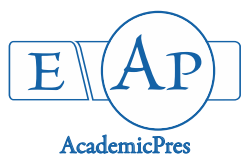

Lavanya N et al. (2021)

Notulae Scientia Biologicae

Volume 13, Issue 2, Article number 10953

DOI: $10.15835 / \mathrm{nsb} 13210953$

Research Article

\title{
Endophytic fungal isolation from Blumea axillaris: Identification and biological activity of secondary metabolites
}

\author{
Nehru LAVANYA ${ }^{1}$, Vellingiri MANON MANI ${ }^{2}$, Nachimuthu \\ SARANYA ${ }^{1}$, Rajendran DEEPAKKUMAR ${ }^{1}$, \\ Kathirvel PREETHI ${ }^{1 *}$
}

\author{
IB Bharathiar University, Department of Microbial Biotechnology, Coimbatore, Tamil Nadu, India; lavanya15394@gmail.com, \\ saranyamicron@gmail.com; deepakbio54@gmail.com;gunpre77@gmail.com (*corresponding author) \\ ${ }^{2}$ Rathnavel Subramaniam College of Arts and Science, Department of Biotechnology, Coimbatore, Tamil Nadu, India; \\ manonmanisathee12@gmail.com
}

\begin{abstract}
Medicinal plants are a wealthy source of natural medicinal properties and remain as base for new drug discoveries. Endophyte from the specific medicinal plants produce the analogous metabolites as that of the host plant. The metabolites from the endophytes comprise maximum therapeutic properties and have been extensively applied in treating various diseases and disorders. This study was focused on identification of the endophytic fungi from the medicinal plant Blumea axillaris and investigates the diversity of endophytic fungi from various explants of the same plant. The explants were cultured on potato dextrose agar and 6 endophytic fungi were successfully isolated from Blumea axillaris. They were identified morphologically and confirmed with molecular analysis as Xylaria arbuscula, Paraphoma radicina, Phomopsis phaseoli, Sordaria fimicola, Aspergillus amstelodami, Diaporthe eucalyptorum. The DNA sequences were analyzed by BLAST and the phylogenetic tree was constructed with neighbor joining method. The six isolates were subjected to antagonistic activity for the selection of potential strain and the bioactive strain Xylaria arbuscula was selected for the production of secondary metabolites by optimization. The parameters like $\mathrm{pH}$, temperature, incubation period, carbon and nitrogen (organic and inorganic source) were optimized for secondary metabolite production. The fungal metabolite was extracted by solvent extraction method using polar and non-polar solvents like propanol, methanol, chloroform, acetone and ethyl acetate. To investigate the bioactivities of the fungal crude extract was subjected first for its antioxidant activity using DPPH radical scavenging method, followed by antimicrobial activity of methanolic $(\mathrm{MeOH})$ extract of Xylaria arbuscula, that were also analyzed by the agar well-diffusion method against the clinical pathogens Staphylococcus aureus, Staphylococcus epidermidis, Enterococcus faecalis, Escherichia coli, Pseudomonas aeruginosa, Klebsiella pnuemoniae, Proteus mirabilis, Aspergillus niger and Candida albicans.
\end{abstract}

Keywords: antioxidant; antimicrobial activity; Blumea axillaris; endophytic fungi; metabolites; molecular analysis

Received: 22 Apr 2021. Received in revised form: 31 May 2021. Accepted: 07 Jun 2021. Published online: 23 Jun 2021.

From Volume 13, Issue 1, 2021, Notulae Scientia Biologicae journal uses article numbers in place of the traditional method of continuous pagination through the volume. The journal will continue to appear quarterly, as before, with four annual numbers. 


\section{Introduction}

Microorganisms, mostly fungi and bacteria inhabit in plant hosts as endophytes for their entire life cycle. Endophytes that are unobtrusive within plants for their life cycle and their hosts develop into parasitic (Selim et al., 2012). Numerous factors such as geographical location, climatic patterns, physiology and specificity of colonized tissue are subjective to endophytic community (Singh et al., 2015). Endophytic fungi generate crucially high impactable secondary metabolites which can be uttered as new drugs (Gond et al., 2007). Bioactive compounds are responsible for destroying the pathogenic disease-causing microbes and researchers believe that endophytes from several plants can produce metabolites which are readily active against diseases (Preethi et al., 2021).

Microbial natural products represent an extensive area for new therapeutic compounds search (Berdy 2012; Newman and Cragg, 2014). On the genetic researches, 95\% of biosynthetic compounds of microorganisms keep handy, which endorse the thrust area of microbial natural products research and even for suitable biodiversity details and for their understanding of mutualistic relationships (Walsh and Fischbach, 2010). Endophytes have been immensely researchable for their antibacterial, antioxidants, anticancer, antidiabetic, antiviral and anti-suppresive activities (Fathima and Balakrishnan, 2014; Gade et al., 2008). It discriminates the plant survival. Host plants without endophyte-fungal association are devastated by the waves of extreme temperature, drought, salinity and pathogen attack (Schulz and Boyle, 2005; Saikkonen et al., 2010; Rodriguez et al., 2012). In the terrain, more 300,000 plant species exist; each individual plant turns as host to the endophytes. Thus, provides a rich pool of microorganisms (Strobel and Daisy, 2003; Bérdy, 2005). Few of endophytic fungal strains are found to exhibit the anti- angiogenesis properties hidden in the metabolites produced by the fungal strains such as Aspergillus terreus and Fusarium oxysporum (Mani et al., 2018).

Blumea axillaris (Lam.) DC (Syn. Blumea mollis (D. Don) Merr, Blumea wightiana DC,) belongs to the family Asteraceae (Tribe Inuleae). It is an annual aromatic herb found in Southeast Asia, south of Sahara and South America (Sreelekha et al., 2017). The plant has several medicinal properties and is used in the treatment of skin diseases, wounds, external parasites, diarrhoea, asthma, and dropsy (Sreelekha et al., 2017). Besides, antiinflammatory, antioxidant, anticancer, antibacterial, anti-phytofungal activities (Sreelekha et al., 2017; Sivanandhan et al., 2018) and mosquito larvicidal activities (Senthilkumar et al., 2008) have been reported for the essential oil and alcoholic extract of this plant. Recently, endophytes are viewed as a rich source of secondary metabolites and bioactive compounds. Endophytic fungi can produce novel bioactive compounds to develop the major application, agricultural and pharmaceutical field. No study has been reported on the biodiversity of endophytes in this plant Blumea axillaris. On this basis, the current study was investigated in analyzing the plant biodiversity of the endophytic fungi isolated from Blumea axillaris of Valparai hills, Coimbatore, Tamil Nadu and extracted the bioactive crude metabolites from a potential endophytic fungus.

\section{Materials and Methods}

\section{Plant sample collection}

The plant Blumea axillaris was collected from the territory of Valparai hills, Coimbatore, Tamil Nadu, India $\left[10.37^{\circ} \mathrm{N}, 76.97^{\circ} \mathrm{E}\right]$ (Figure 1 ). The sample was collected and preserved in a sealed plastic bag under $4{ }^{\circ} \mathrm{C}$ until processing. Plant samples were scrupulously washed in running tap water to remove soil particles and adhered debris. Then they were dried on the paper towel and different parts of the plant like root, stem, leaf and flower were taken for analysis. The analysis includes endophytic fungal isolation from this explant. The explants were cut into small pieces of $<1 \mathrm{~cm}$. The first step of analysis started with surface sterilization of the explants which were washed in $70 \%$ ethanol for $1 \mathrm{~min}$, in $50 \%$ sodium hypochlorite solution for $3 \mathrm{~min}$ and $70 \%$ ethanol for 30s before processing (Vigneshwari et al., 2019). 

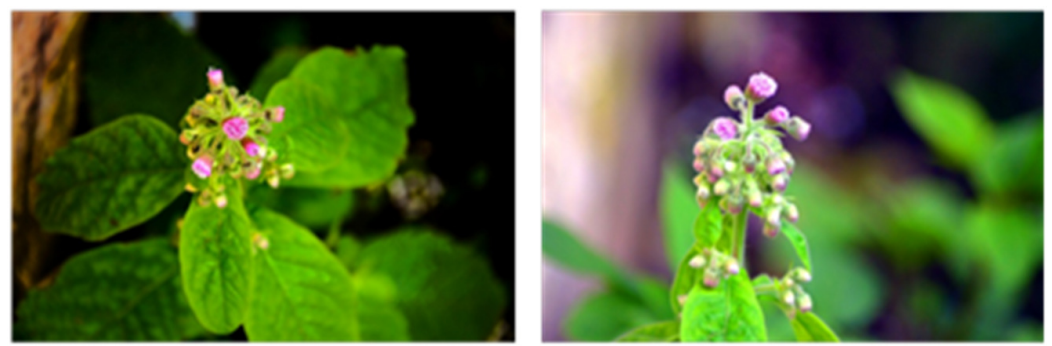

Figure 1. Plant sample (Blumea axillaris)

\section{Isolation of endophytic fungi}

Following surface sterilization, each piece of the explants was cut to expose their inner tissue and placed on Potato Dextrose Agar (PDA), supplemented with $50 \mathrm{mg} / \mathrm{L}$ chloramphenicol to suppress bacterial growth. All the plates were incubated at $25^{\circ} \mathrm{C}$ for up to 7-10 days with daily monitoring for fungal colonies. Pure fungal isolates were acquired by picking individual colonies from the PDA plates and plating on fresh PDA medium under similar incubation for 10 days (Mani et al., 2015a). Each fungal culture was ensured for purity and transferred separately to PDA slants and maintained at $4{ }^{\circ} \mathrm{C}$.

\section{Statistical analysis of the isolated endophytic fungi}

The colonization frequency (\%CF) of endophytic fungi was calculated using the formula by (Kharwar et al., 2011): \%CF = Ncol/Nt x100. Where, Ncol- Number of segments colonized by each fungus, $\mathrm{Nt}-$ Total number of segments studied.

Simpson's and Shannon-wiener diversity indicates were calculated as per formula (Kharwar et al., 2011): Simpson's Diversity $(\mathrm{D})=1-\sum(\mathrm{pi})^{2}$; Shannon-wiener diversity $(\mathrm{H})=-\sum \mathrm{s}(\mathrm{pi} \log \mathrm{pi})$; Where, pi- proportion of frequency of colonization of the 'i' species in the sample. Sample richness was calculated as follow (Kharwar et al., 2011). $S=$ species richness i.e., total number of species.

\section{Screening for potential strains}

The potentiality of the endophytic fungi was measured based on its antagonistic activity. To check the antagonistic activity four days old fungal culture was streaked on the centre of PDA, MEA and SDA media plates and incubated for $48 \mathrm{~h}$ at $28 \pm 2{ }^{\circ} \mathrm{C}$. The antagonistic activity of endophytic fungal strains against Staphylococcus aureus, Staphylococcus epidermidis, Enterococcus faecalis, Escherichia coli, Pseudomonas aeruginosa, Klebsiella pnuemoniae, and Proteus mirabilis were tested by dual culture technique (Cross streak method) (Mani et al., 2015b). Correspondingly, the fungal pathogens (Ascomycota) such as Aspergillus niger and Candida albicanswere also studied. Bacterial isolates were streaked on either side of the line streaked fungal culture (one $\mathrm{cm}$ away from the centre). Observation of inhibition zone width and mycelia growth of test pathogen was recorded (Fokkema, 1978; Mani et al., 2017).

\section{Screening of culture medium, Production and crude extraction}

The fungal strains were inoculated in different media such as Potato Dextrose Broth (PDB), Sabouraud dextrose broth (SDB), malt extract broth (MEB), and Czapek Dox broth (CDB) to determine the maximum production inducing media. The flasks were kept in stationary phase and in shaking condition at $100 \mathrm{rpm}$ for 11-15 days at $28 \pm 2{ }^{\circ} \mathrm{C}$ incubation in light and dark cycle. After incubation, the total productions were extracted from biomass and culture filtrate by solvent extraction method using polar and non-polar solvents. The total yield of crude metabolites was evaluated using (Formula 1) (Mani et al., 2015a). 


\section{Measurement of biomass}

The biomass was separated and washed twice with distilled water. The biomass was kept for drying in hot air oven at $40-50^{\circ} \mathrm{C}$ for 5 hours and then dried in desiccators before weighing for dry cell weight $(\mathrm{x})$. The results were expressed in gram per litre (Vellingiri et al., 2021).

\section{Estimation of intracellular crude metabolite production}

Intracellular crude metabolite production was estimated for every 3 days from the day of inoculation. One gram of fresh biomass was taken and was well ground in a homogenizer. Further it was well ground by adding pure methanol. The clear supernatant solution was taken and stored in a one litre flask. The process was repeated by using 20-25 gm of fungal biomass and the clear supernatant was made up to one litre. The extract was concentrated in rotary vacuum evaporator and each portion was stored in $5 \mathrm{ml}$ of methanol. Then the crude extract stored was taken and absorbance value was measured from 200 to $800 \mathrm{~nm}$ using UV-Vis spectrophotometer (Vellingiri et al., 2021).

\section{Estimation of extracellular crude metabolite production}

The culture filtrate was taken at an interval of 3 days from the day of inoculation. The fungal metabolites were extracted by solvent extraction method using methanol as solvent. Equal volumes of culture filtrate and solvent were taken in a separating funnel and shaken vigorously for 5 minutes and then allowed to settle for 5 minutes, the same procedure was repeated for 5 times and then organic phase was collected. The filtrate was extracted thrice with an equal volume of methanol $(1: 1 \mathrm{v} / \mathrm{v})$. The solvent was then evaporated using a rotor evaporator at $40^{\circ} \mathrm{C}$ for $20-40 \mathrm{~min}$ and the residual compound was dried. The dried compound was mixed with $5 \mathrm{ml}$ of methanol and stored. The crude metabolite was collected and the absorbance was recorded in a spectrophotometer from 200 to $800 \mathrm{~nm}$.

\section{Evaluation of total crude metabolite production}

The production of crude metabolite was evaluated on the basis of the following parameters; total absorbance of intra and extra cellular metabolites $\left(\mathrm{Abs}_{\mathrm{T}}\right)$; yield factor of crude metabolites on cell growth $(\mathrm{Yp} / \mathrm{x})$. Formula 1: $\left\{\mathrm{Abts}_{\mathrm{T}}=\mathrm{Abs} \mathrm{s}_{\text {intra }}+\mathrm{Abs}_{\text {extra }}\left[A b s_{\text {intra }}=A b s_{\text {extract }} \times \mathrm{D}, \mathrm{D}=50 \mathrm{~V}, \mathrm{Y}_{\mathrm{p} / \mathrm{x}}=\Delta \mathrm{Abts_{ \textrm {T } }} / \Delta \mathrm{x}\right] ; \mathrm{Ab} s_{\mathrm{T}}\right.$ : Absorbance of extra-plus intracellular pigments $(\mathrm{U}) ; \mathrm{Abs}_{\mathrm{extra}}$ and $\mathrm{Abs}_{\text {intra: }}$ extracellular and intracellular absorbance $(\mathrm{U})$; $\mathrm{Abs}_{\text {extract: }}$ absorbance in the extract of cell disruption $(\mathrm{U})$; $\mathrm{V}$ : volume of the sample submitted to cell disruption for pigment extraction $(\mathrm{mL})$; $\mathrm{x}$ : cell concentration $(\mathrm{g} / \mathrm{L}) ; \mathrm{Yp} / \mathrm{x}$ : yield factor of pigments on cell growth (UL/g)\} (Mani et al., 2015a; Vellingiri et al., 2021). The total crude extract of each strain was concentrated in rotary vacuum evaporator and it was taken for further studies.

\section{Fungal identification}

Microscopic identification

The fungal strains were identified by lactophenol cotton blue method. On a clean microscopic glass slide the fungal specimen was placed using sterile inoculation loop; one or two drops of Lactophenol Cotton Blue Solution was added and a cover glass was placed over the stained samples (Xu et al., 2008; Mani et al., 2015b). The prepared slides were examined under bright field microscope.

\section{Molecular method of identification}

The genomic DNA was isolated from the fungal cultures using the EXpure Microbial DNA isolation kit developed by Bogar Bio Bee stores Pvt Ltd. Molecular analysis was done using amplification of ITS1 and ITS4 fragments of rDNA. 18s rRNA or rDNA sequence analysis was performed using specific polymerase chain reaction (PCR) primers to amplify rDNA fragments of endophytes that was used to validate the morphospecies of different groups of mycelia (Doss et al., 1995 and Lacap et al., 2003). The sequencing was done by NCBI blast similarity search tool. The phylogeny analysis of query sequence with the closely related 
sequence of blast results were performed followed by multiple sequence alignment. The program MUSCLE 3.7 was exploited for multiple alignments of sequences (Edgar, 2004). The resulted aligned sequences were cured using the program Gblocks $0.91 \mathrm{~b}$. This Gblocks eliminated poorly aligned positions and divergent regions (removes alignment noise) (Talavera and Castresana, 2007). Finally, the program PhyML 3.0 aLRT was used for phylogeny analysis and HKY85 as Substitution model. PhyML was shown to be the least accurate with other existing phylogeny programs using simulated data, while being one order of magnitude faster. The program Tree Dyn 198.3 was used for tree rendering (Dereeper et al., 2008).

\section{Screening for antioxidant activity}

The antioxidants present in fungal crude extracts were aliquoted into different concentrations (20 200 $\mu \mathrm{g} / \mathrm{ml}$ ) to determine the ability to scavenge 2,2-diphenyl-1-picrylhydrazyl (DPPH) radicals using the method of (Yildirim et al., 2001). DPPH solution (1 mM DPPH radical solution in $95 \%$ methanol) was added to the aliquots of crude extracts and made up to $1 \mathrm{~mL}$, vortexed well and then incubated for $30 \mathrm{~min}$ in dark chamber at room temperature (RT). After incubation, the samples were taken into microfuge tubes and centrifuged for $5 \mathrm{~min}$ at 13,500 rpm at RT. The absorbance of each sample at $\lambda=517 \mathrm{~nm}$ was measured and $1 \mathrm{~mL}$ of $95 \%$ $\mathrm{MeOH}$ was used as a control, and ascorbic acid as standard. The antioxidant activity was given in percentage inhibition (\%).

DPPH scavenging assay was calculated by using the formula: [(control absorbance - extract absorbance)/ (control absorbance) $\times 100]$.

\section{Analysis of antibacterial and antimycotic activity}

Antimicrobial assessment for the concentrated crude biomass extract and cell free culture filtrate extract of each potential isolates were determined by well-diffusion method (Bauer et al., 1966; Barry et al., 1970) against clinical pathogens $S$. aureus, $S$. epidermidis, E. faecalis, $E$. coli, $P$. aeruginosa, $K$. pnuemoniae, and $P$. mirabilis on Muller-Hinton agar (MHA) media. Forty micrograms of aliquots of extracts were filled in the respective wells. The diameter of inhibition zone was measured after $24 \mathrm{hr}$ of incubation at $37^{\circ} \mathrm{C}$ for bacterial cultures. Antimycotic activity was determined by well diffusion technique using clinical fungal pathogens $A$. niger and $C$. albicans by swabbing on MHA plate and by filling $40 \mu \mathrm{l}$ of aliquots of extracts in the respective wells. The plates were incubated for $48 \mathrm{hr}$ at $28 \pm 2{ }^{\circ} \mathrm{C}$ and then zone of inhibition was deliberated.

\section{Media optimization}

\section{Screening of culture media}

The fungal strain was inoculated in different media such as SDB, PDB, MEB, CDB and oat meal broth to screen the best media for fungal mat growth and biomass dry weight. Inoculated media were plugged with non-absorbent cotton and were incubated for 21 days at $28^{\circ} \mathrm{C}$ (Mani et al., 2015b). After 21 days, the best media was selected from the result and taken further studies.

\section{Effect of $p H$, temperature and incubation period}

The effect of $\mathrm{pH}$ on the crude metabolite and biomass production was performed in the selected best media by varying $\mathrm{pH}$ from $\mathrm{pH} 3$ to $\mathrm{pH}$ 9. The $\mathrm{pH}$ was adjusted using $0.1 \mathrm{~N} \mathrm{HCL}$ and $0.1 \mathrm{~N} \mathrm{NaOH}$. The medium was inoculated with the strain and incubated at $28^{\circ} \mathrm{C}$ for 21 days (Naik et al., 1988; Vellingiri et al., 2021). The effect of temperature on the crude metabolites and biomass production was studied by incubating the best media containing inoculums, at different temperatures such as $15^{\circ} \mathrm{C}, 25^{\circ} \mathrm{C}, 35^{\circ} \mathrm{C}, 45^{\circ} \mathrm{C}$ and $55^{\circ} \mathrm{C}$ for 21 days (Ripa et al., 2009). The incubation period was optimized with regular intervals of 3 days for a period of 30 days was attempted with the inoculation of fungal strains in the best media. Mycelium was harvested from $100 \mathrm{ml}$ of culture at an interval of every 3 days, separated and filtered through Whatmann No.1 filter paper. Then it was washed twice in distilled water and dried and the weight of the harvested mycelium from all the 
inoculated flasks in $\mathrm{pH}$, temperature and incubation period were determined. The total yields of crude metabolites were evaluated using the formula 1.

\section{Effect of carbon and nitrogen source}

The effect of various carbon sources on the crude metabolites and biomass production was analysed in the selected best media by replacing the carbon source in the medium (Vellingiri et al., 2021). The organic carbon sources such as cassava powder, wheat bran powder, corn powder, sweet potato pulp, rice porridge and inorganic carbon sources like lactose, dextrose, maltose, sucrose, glycerol were used the study (Majumdar and Majumdar, 1965). The organic nitrogen sources such as neem oil cake, Cotton seed oil cake, ragi powder, sesame oil cake, coconut oil cake and inorganic nitrogen source such as ammonium sulphate, peptone, sodium nitrate, casein and yeast extract powder were used for the study (Singh et al., 2009). The medium was inoculated with inoculums and incubated for 21 days at optimum temperature. The biomass from the culture broth was separated, filtered and dried. The dried biomass was weighed. The crude metabolite production was also evaluated.

\section{Results}

\section{Isolation of endophytic fungi}

About six fungal strains were isolated from the various explants of $B$. axillaris. The statistical analysis of the isolated endophytic fungi was given in (Table 1). Phomopsis phaseoli and Paraphomo radicina are isolated from the stem. Sordaria fimicola, Diaporthe eucalyptorum, Aspergillus amstelodami, Xylaria arbuscula were isolated from the leaf, flower and root respectively. Those endophytes have different endophytic diversity in comparison to $B$. axillaris.

Table 1. Colonization rate of endophytic fungi isolated from Blumea axillaris from Valparai hills, Tamil Nadu

\begin{tabular}{|l|c|c|c|c|c|}
\hline \multirow{4}{*}{} & \multicolumn{4}{|c|}{ Name of the explants } & \multirow{2}{*}{ Colony frequency \% } \\
\cline { 2 - 5 } & Root & Stem & Leaves & Flowers & 16.66 \\
\cline { 2 - 6 } $\begin{array}{l}\text { Various types } \\
\text { of colonies } \\
\text { found }\end{array}$ & NLR & & & & 33.33 \\
\cline { 2 - 6 } & & NLS3 & & & 33.33 \\
\cline { 2 - 6 } & & NLS4 & & NLF & 16.66 \\
\cline { 2 - 6 } & & & & NLL & 33.33 \\
\hline
\end{tabular}

\section{Fungal identification}

The six endophytic fungal strains in different explants of $B$. axillaris were identified by colony morphology and microscopic method given in (Table 2). All the endophytic fungal strains were identified by $18 \mathrm{~S}$ rRNA gene sequencing. Amplified ITS rDNA region of selected isolated NLR, NLS3, NLS4, NLL, NLF, and NLF2 were sequenced and compared with the sequences of organisms represented in the NCBI database gene bank using BLAST search to generate a phylogenetic tree (Figures 2, 3, 4). High resemblance sequences were included for alignment and bootstrapping using CLUSTAL X. The generated dendrogram showed that isolated endophytes belong to the diverse fungal group. The pattern of branching in a phylogenetic tree reflected how species or other groups evolved from a series of common ancestors. In phylogenetic tree, two species were more correlated if they have an added recent common ancestor and less related if they have a less recent common ancestor and phylogenetic tree are given in (Table 2). 
Table 2. Morphological and molecular identities of the endophytes isolated from B. axillaris

\begin{tabular}{|c|c|c|c|c|}
\hline $\begin{array}{l}\text { Strain } \\
\text { name }\end{array}$ & Microscopic identification & Morphological characterization & \% Similarity & $\begin{array}{c}\text { Gene bank } \\
\text { accession } \\
\text { number }\end{array}$ \\
\hline NLR & & $\begin{array}{l}\text { Colonies grown with pronounced } \\
\text { concentric rings of slightly raised, } \\
\text { yellow-tan to orange-tan mycelium } \\
\text { alternating with broader bands of } \\
\text { appressed white mycelium. Less } \\
\text { gregarious, sterile stromal apex and } \\
\text { smooth ectostromata. They are yellow, } \\
\text { becoming black at maturity } \\
\text { conidiophores of a palisade form and } \\
\text { stipitate fruit bodies without } \\
\text { producing a hypoxyloid form (Rogers } \\
\text { and Samuels, 1986) }\end{array}$ & $\begin{array}{l}100.00 \% \\
\text { MK333984. } \\
1\end{array}$ & MN904863 \\
\hline NLS3 & & $\begin{array}{l}\text { Colony diameter } 15 \mathrm{~mm} \text { after } 1 \text { week; } \\
\text { aerial mycelium floccose, white greyish. } \\
\text { Colony pigmentation after } 2 \text { weeks } \\
\text { olivaceous gray at the margin and dark } \\
\text { vinaceous in the center. Reverse similar. } \\
\text { Margins regular or slightly regular. } \\
\text { Conidiomata pycnidial, ostiolate, } \\
\text { unilocular and solitary, sub- merged in } \\
\text { agar, obpyriform, semi-pilose, pale to } \\
\text { dark brown; Conidial matrix cream } \\
\text { colored; pycnidial cellwall 10to15mm } \\
\text { thick, micro pycnidia abundant and } \\
\text { submerged in the medium, pale brown. } \\
\text { Conidiophores reduced to phialidic } \\
\text { conidiogenous cells, hyaline, smooth } \\
\text { and ampulliform (Moslemi et al., 2016) }\end{array}$ & $\begin{array}{l}99.27 \% \\
\text { MH425313. } \\
1\end{array}$ & MN904864 \\
\hline NLS4 & & $\begin{array}{l}\text { Colonies on OA flat, spreading with } \\
\text { sparse dirty-white aerial mycelium; } \\
\text { surface and reverse with diffuse patches } \\
\text { of fuscous-black and dirty-white; } \\
\text { colonies on PDA flat, spreading, with } \\
\text { sparse, dirty-white aerial mycelium at } \\
\text { the edge of the dish; surface and reverse } \\
\text { having a translucent to ochreous } \\
\text { central part; outer region umber (Johan } \\
\text { et al., 2006). }\end{array}$ & $\begin{array}{l}100.00 \% \\
\text { KF435154.1 }\end{array}$ & MN904865 \\
\hline
\end{tabular}




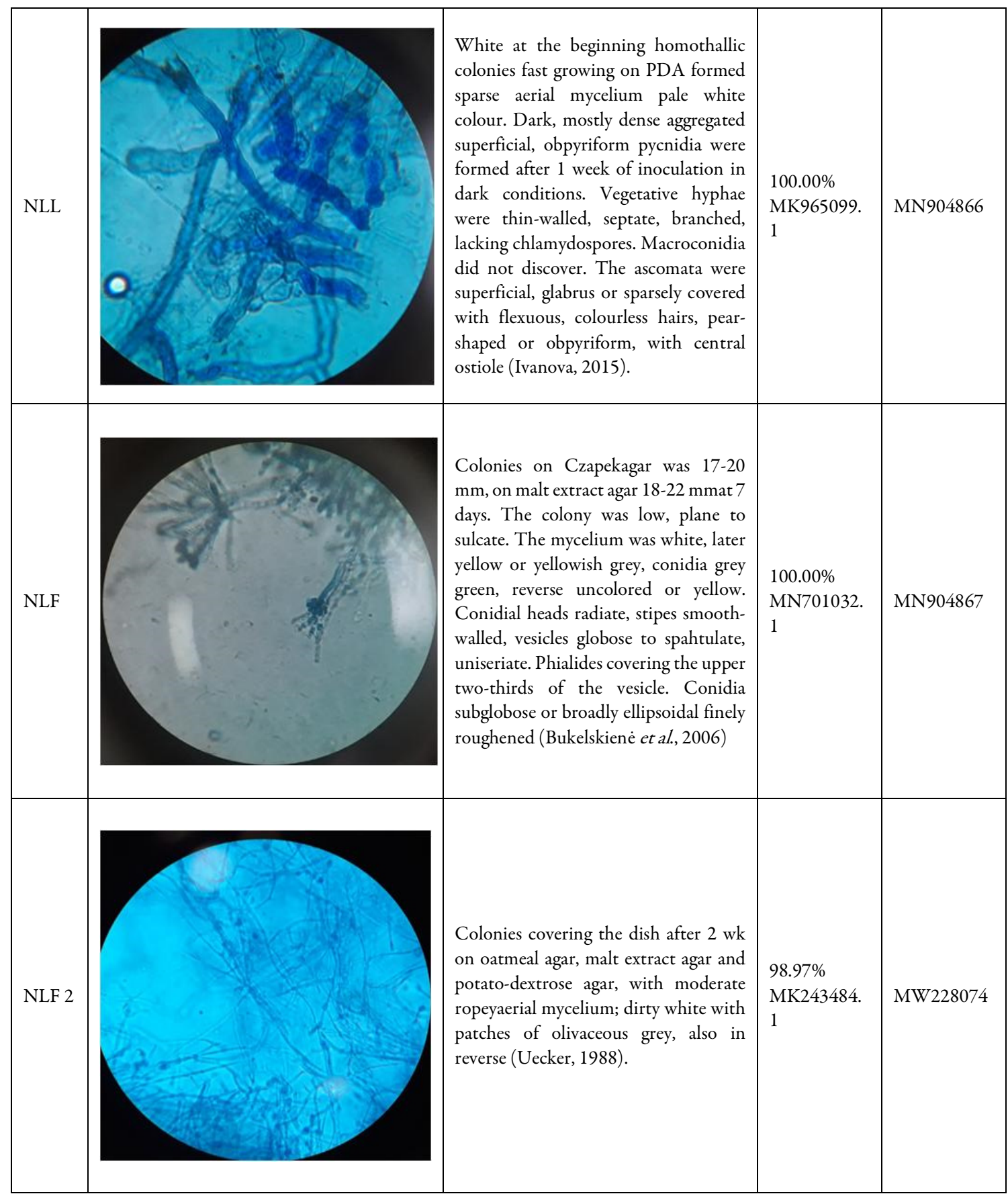




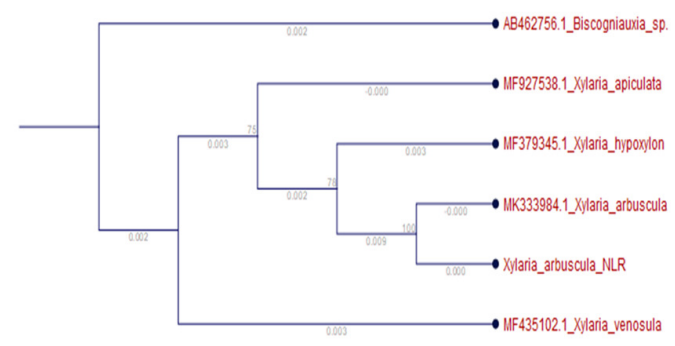

A

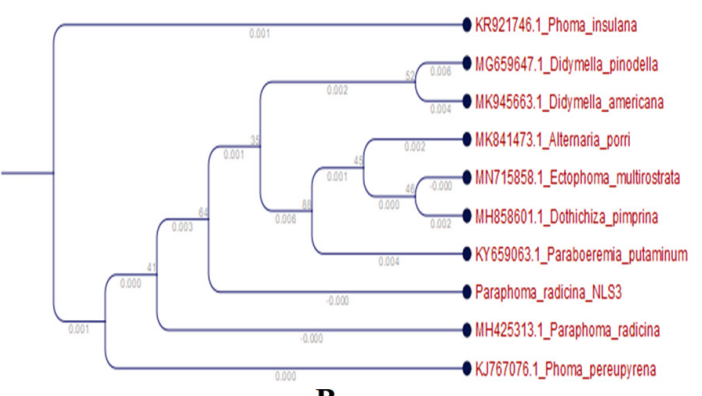

B

Figure 2. Phylogenetic tree for A) Xylaria arbuscula, B) Paraphomo radicina
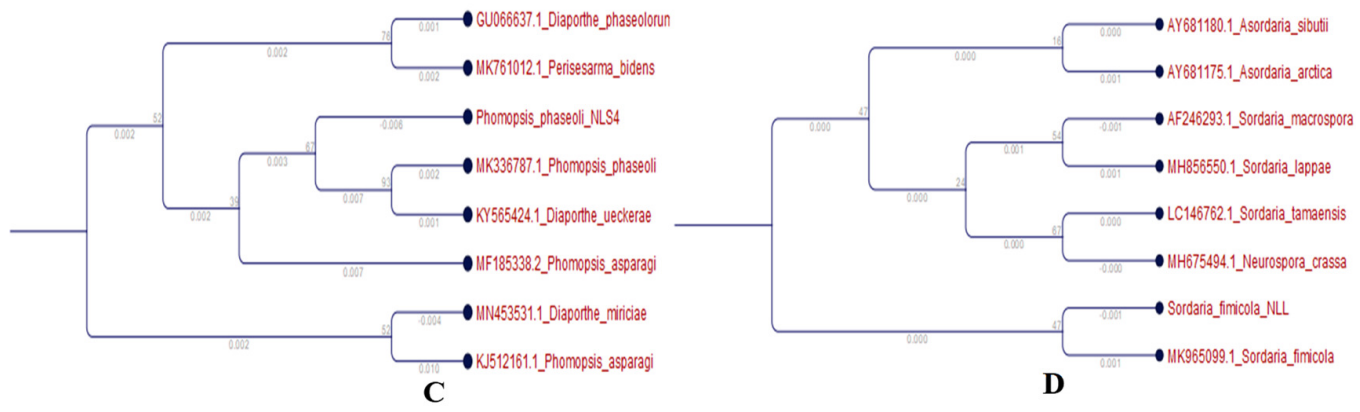

Figure 3. Phylogenetic tree for C) Phomopsis phaseoli, D) Sordaria fimicola

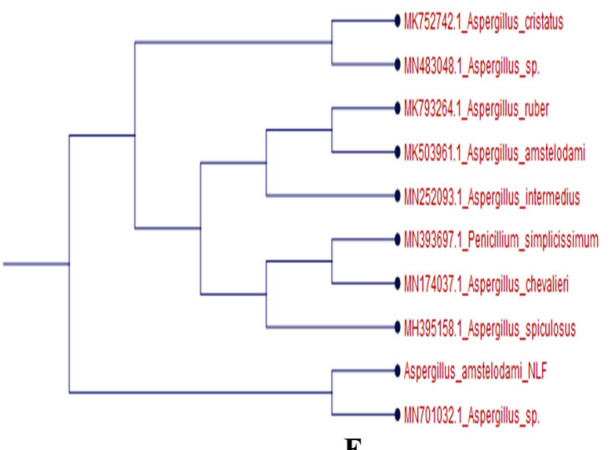

$\mathbf{E}$

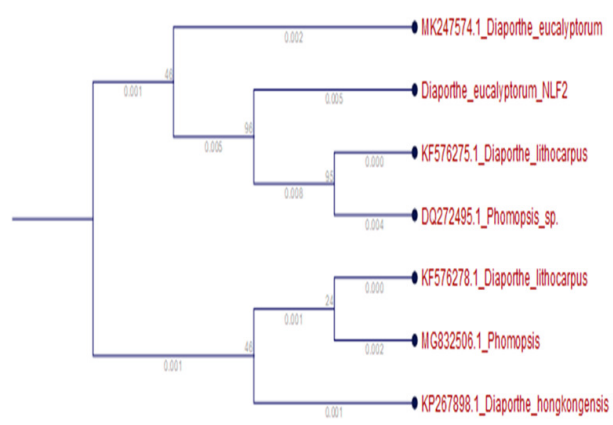

$\mathbf{F}$

Figure 4. Phylogenetic tree for E) A. amstelodami and F) D. eucalyptorum

\section{Screening for potential strains}

The isolated endophytic fungal strains were screened for their antagonistic activity against the pathogens through dual culture technique. During the antagonistic studies NLR (Xylaria arbuscula) strain found to exhibit highest inhibitory activity against bacterial pathogens $S$. aureus, S. epidermidis, E. faecalis, E. coli, $P$. aeroginosa, $K$. pnuemoniae and $P$. mirabilis and also negative inhibition towards the fungal pathogens. Among the six endophytic fungi tested $X$. arbuscula showed the maximum antagonistic activity against the most pathogens (Table 3).

\section{Screening of culture media and Extraction of crude metabolites}

Endophytic fungi were inoculated in different media such as PDB, SDB and MEB. The gross fungal mat (biomass) produced within the incubation period of 21 days was highest in the Malt Extract Broth when compared with other media. All the 6 endophytic fungal isolates were screened for the culture media for the 
induction of metabolites in a range of 11-21 days of incubation. $X$. arbuscula was the preeminent strain that showed the maximum metabolite production with $11.09 \mathrm{UL} / \mathrm{g}$ in MEB (Table 4).

The intracellular and extracellular metabolite production was estimated after the inoculation period at stationary phase through solvent extraction process. The methanol extraction for the fungal biomass showed highest absorbance spectrophotometrically; using the solvents; propanol, methanol, chloroform, acetone and ethyl acetate (Table 5). The cell filtrate extraction did not show any metabolite production.

Table 3. Screening for antagonistic activity for endophytic fungal isolates

\begin{tabular}{|l|c|c|c|c|c|c|c|c|c|}
\hline \multirow{2}{*}{$\begin{array}{c}\text { Endophyt } \\
\text { ic fungal } \\
\text { isolates }\end{array}$} & \multicolumn{8}{|c|}{ Diameter of zone of inhibition against human pathogens(cm) } \\
\cline { 2 - 11 } & $\begin{array}{c}S . \\
\text { aureus }\end{array}$ & $\begin{array}{c}S . \\
\text { epidermidis }\end{array}$ & $\begin{array}{c}E . \\
\text { faecalis }\end{array}$ & $\begin{array}{c}E . \\
\text { coli }\end{array}$ & $\begin{array}{c}P . \\
\text { aeroginosa }\end{array}$ & $\begin{array}{c}K . \\
\text { pnuemoniae }\end{array}$ & $\begin{array}{c}P . \\
\text { mirabilis }\end{array}$ & $\begin{array}{c}A . \\
\text { niger }\end{array}$ & $\begin{array}{c}C . \\
\text { albicans }\end{array}$ \\
\hline NLF & 0.8 & 1.1 & - & 0.4 & - & 0.7 & 0.6 & - & - \\
\hline NLF2 & 1.2 & - & - & 0.7 & - & 1.3 & 0.9 & - & - \\
\hline NLS3 & 0.9 & - & - & - & 0.2 & 1.2 & 0.8 & - & - \\
\hline NLS4 & - & - & 0.5 & 1.4 & - & 1.8 & 0.4 & - & - \\
\hline NLR & 3.7 & 2.7 & 3.1 & 3.4 & 2.9 & 2.7 & 3.8 & - & - \\
\hline NLL & 1 & 2.2 & 2.5 & 1.5 & 2.1 & 1.9 & 0.9 & - & - \\
\hline
\end{tabular}

Table 4. Screening for culture media

\begin{tabular}{|l|c|c|c|c|c|c|}
\hline \multirow{3}{*}{ Strain name } & \multicolumn{2}{|c|}{ PDB culture medium } & \multicolumn{2}{c|}{ SDB culture medium } & \multicolumn{2}{c|}{ MEB culture medium } \\
\cline { 2 - 7 } & $\begin{array}{c}\text { GFM } \\
\mathrm{g} / \mathrm{L}\end{array}$ & $\begin{array}{c}\text { CMP } \\
\mathrm{UL} / \mathrm{g}\end{array}$ & $\begin{array}{c}\text { GFM } \\
\mathrm{g} / \mathrm{L}\end{array}$ & $\begin{array}{c}\text { CMP } \\
\text { UL/g }\end{array}$ & $\begin{array}{c}\text { GFM } \\
\mathrm{g} / \mathrm{L}\end{array}$ & $\begin{array}{c}\text { CMP } \\
\text { UL/g }\end{array}$ \\
\hline NLF & 1.01 & 0.36 & 3.2 & 4.2 & 1.21 & 0.85 \\
\hline NLF2 & 2.25 & 1.22 & 2.1 & 0.5 & 2.1 & 0.5 \\
\hline NLS3 & 2.41 & 1.1 & 3.11 & 0.78 & 5.12 & 2.34 \\
\hline NLS4 & 1.2 & 0.23 & 2.1 & 1.45 & 3.24 & 0.61 \\
\hline NLR & 8.7 & 5.55 & 9.87 & 4.76 & 11.09 & 5.98 \\
\hline NLL & 5.6 & 4.11 & 1.98 & 1.23 & 0.23 \\
\hline \multicolumn{7}{|l|}{} \\
\hline
\end{tabular}

Table 5. Rate of extracted crude metabolites

\begin{tabular}{|l|c|c|c|c|c|}
\hline \multirow{2}{*}{ Strain name } & \multicolumn{5}{|c|}{ Absorbance of total crude metabolites (in OD units) } \\
\cline { 2 - 6 } & Propanol & Methanol & Chloroform & Acetone & Ethyl acetate \\
\hline NLF & 0 & 0 & 0.22 & 0.14 & 0.82 \\
\hline NLF2 & 0 & 0.55 & 0.31 & 0.2 & 0 \\
\hline NLS3 & 0.12 & 0.5 & 0.43 & 0.32 & 0 \\
\hline NLS4 & 0 & 0 & 0 & 0.21 & 0.18 \\
\hline NLR & 0.7 & 2.27 & 1.2 & 1.87 & 0.58 \\
\hline NLL & 0.54 & 0.6 & 0 & 0 & 0.11 \\
\hline
\end{tabular}

\section{Media optimization for crude metabolite production}

\section{Screening of culture medium}

Five different media was used to determine the best culture medium for the fungal strain $X$. arbuscula. The best medium was selected on the basis of maximum growth of fungal biomass and the crude metabolite production. Malt extract broth showed highest biomass and crude metabolite production of $10.95 \mathrm{~g} / \mathrm{L}$ and $5.98 \mathrm{UL} / \mathrm{g}$ respectively after 21 days of inoculation. So MEB medium was used for the growth of fungal strain $X$. arbuscula (Figure 5). 


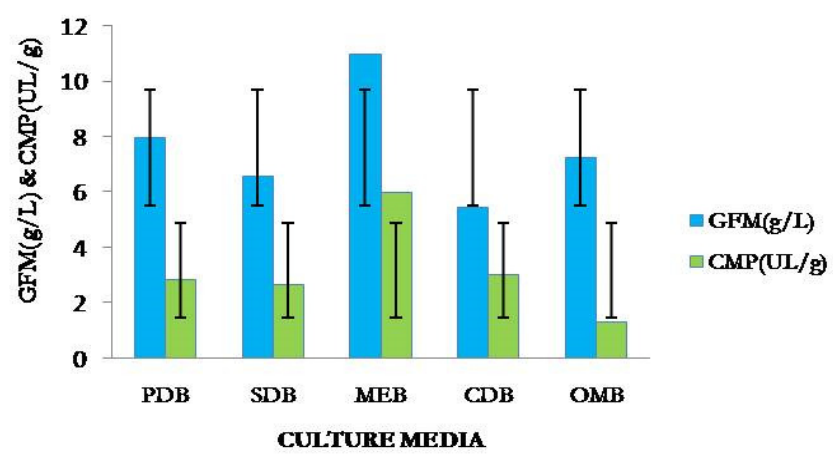

Figure 5. Screening of culture media for the growth of NLR

Values are in Mean \pm SD ( $n=3)$.PDB, potato dextrose broth; SDB, Sabouraud's dextrose broth; CDB, Czapek Dox broth; MEB, malt extract broth; GFM, growth of fungal mat in grams; CMP, crude metabolites production in grams.

\section{Effect of $p H$, temperature and incubation period}

A wide range of $\mathrm{pH}$ was taken to assess the fungal biomass from $\mathrm{pH} 3$ to 9 . The $\mathrm{pH} 5$ and 8 exhibited a stronger metabolite yield with $9.26 \mathrm{~g} / \mathrm{L}$ and $5.24 \mathrm{UL} / \mathrm{g}-9.35 \mathrm{~g} / \mathrm{L}$ and $5.65 \mathrm{UL} / \mathrm{g}$ respectively along with highest growth of fungal mat when compared to other $\mathrm{pH}$ range. The second parameter Temperature was analysed at a range of $15,25,35,45$ and $55^{\circ}$. The strain $X$. arbuscula engendered a significant change at the range of 25 degree Celsius with a fungal biomass of $6.5 \mathrm{~g} / \mathrm{L}$ and metabolite production of $3.68 \mathrm{UL} / \mathrm{g}$ and this was considered to be the optimum temperature.

The strain was further analysed till 30th day of incubation period the mycelium was harvested at an interval of 3 days. The growth was sparse till 12th day and a steady increase was noted from 15 th to 24 th day, after 24th day the yield remains stable. So, the best yield was obtained from 21 to 24th day with the highest metabolite and biomass production of $9.72 \mathrm{~g} / \mathrm{L}$ and $5.35 \mathrm{UL} / \mathrm{g}$ (Figure 6).
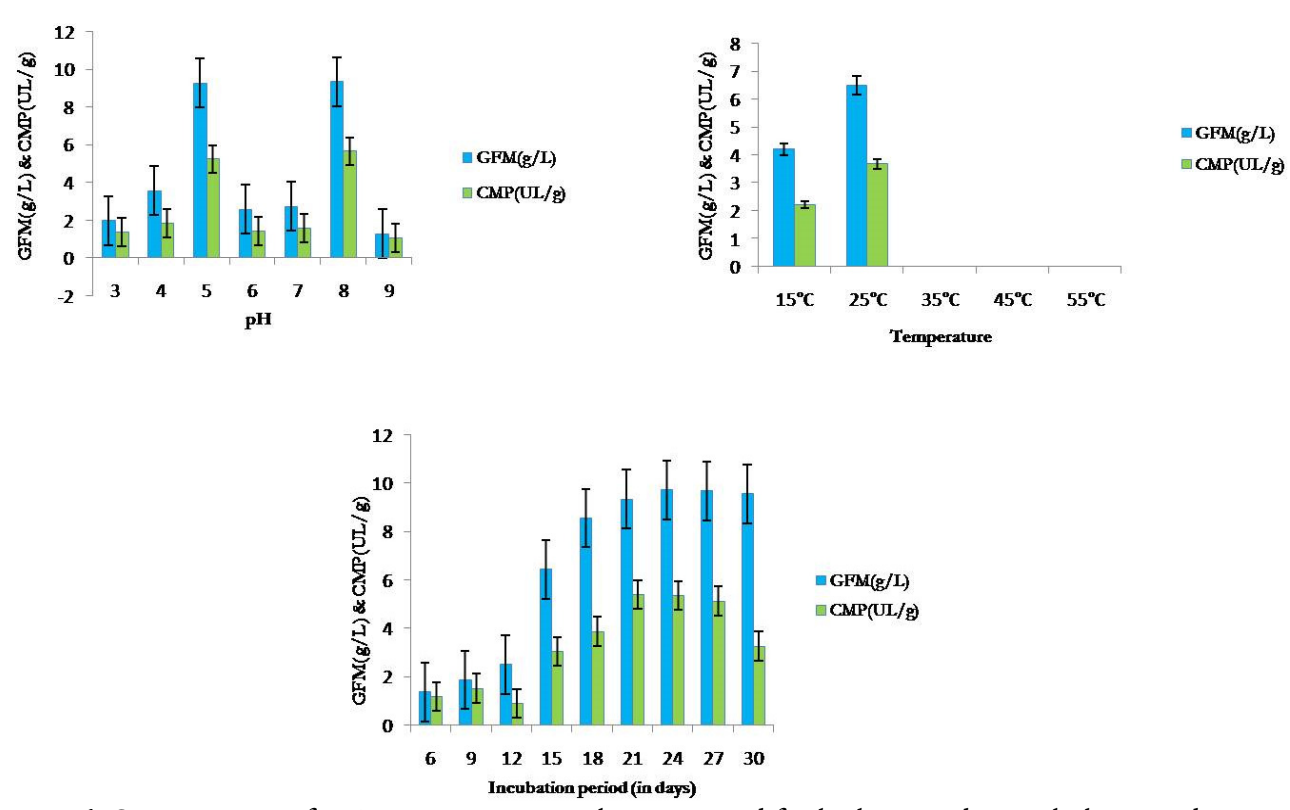

Figure 6. Optimization of $\mathrm{pH}$, temperature, incubation period for highest crude metabolites production in NLR

Values are in Mean \pm SD $(n=3)$. GFM: Growth of fungal mass; CMP: Crude Metabolites Production. 


\section{Effect of carbon and nitrogen source}

The effect of nutritional factors like carbon and nitrogen were analysed by providing 10 different organic and inorganic carbon and nitrogen sources. The highest yield was observed in media supplemented with carbon sources such as Cassava powder and glycerol with the yield of biomass production and crude metabolites 9.57 $\mathrm{g} / \mathrm{L}$ and $5.83 \mathrm{UL} / \mathrm{g}-9.27 \mathrm{~g} / \mathrm{L}$ and $5.42 \mathrm{UL} / \mathrm{g}$ respectively. Regarding the nitrogen sources analysed Sesame oil cake and Peptone were found to be the best nitrogen sources for the strain $X$. arbuscula. The highest metabolite production was obtained in the media supplemented with the yield of $10.03 \mathrm{~g} / \mathrm{L}$ and $5.41 \mathrm{UL} / \mathrm{g}-9.28 \mathrm{~g} / \mathrm{L}$ and $4.15 \mathrm{UL} / \mathrm{g}$ respectively (Figure 7).
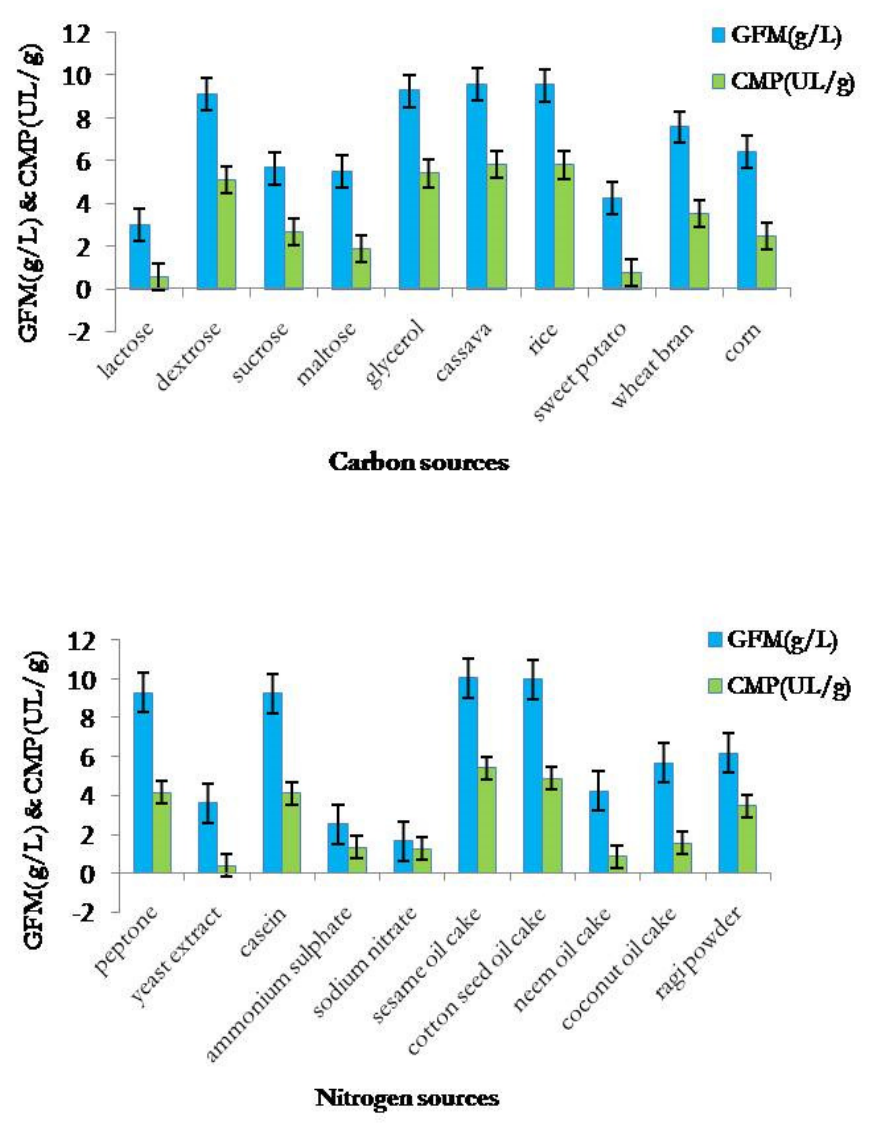

Figure 7. Optimization for NLR of carbon and nitrogen sources

Values are in Mean \pm SD ( $n=3)$. GFM: Growth of fungal mass; CMP: Crude Metabolites Production.

\section{Screening for antioxidant analysis}

DPPH radical scavenging assay is the best known accurate and frequently employed methods for evaluating antioxidant activity. This method is based on the reduction of DPPH in the presence of a radical scavenger or hydrogen donors due to the formation of non radical form of DPPH. The inhibition activity of the fungal crude metabolites at different concentrations such as 20,40,60,80 and $100 \mu \mathrm{g} / \mathrm{ml}$ were determined using ascorbic acid as standard. The crude extract of Xylaria arbuscula exhibited highest antioxidant activity with an $\mathrm{IC}_{50}$ value of $40.92 \mu \mathrm{g} / \mathrm{ml}$ compared to the standard ascorbic acid (Figure 8). 


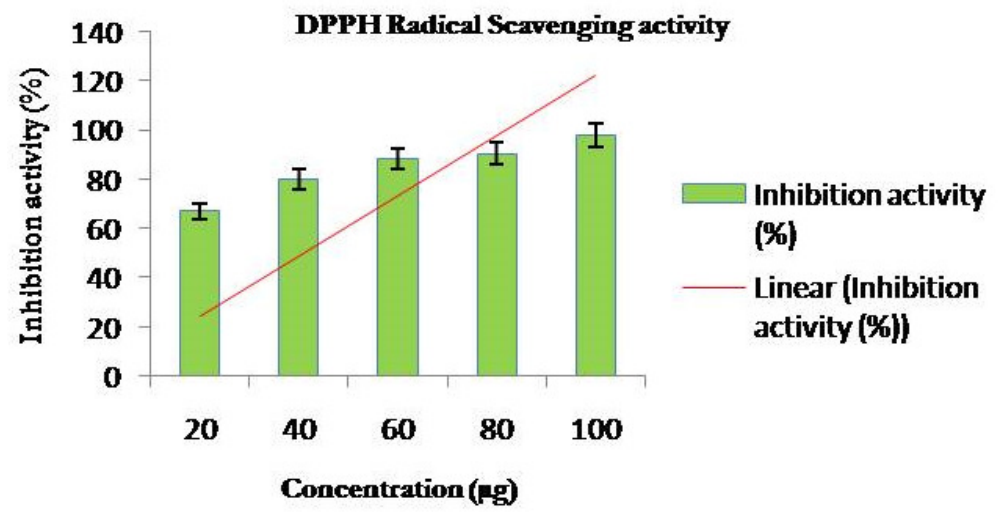

Figure 8. DPPH radical scavenging activity of CMP from $X$. arbuscula (NLR)

\section{Analysis of antibacterial and antimycotic activity}

The fungal crude extract of the strain Xylaria arbuscula was tested for the antimicrobial activity through well diffusion method. The preliminary antimicrobial screening was carried out against 7 bacterial and 2 fungal pathogens on the solid media (MHA). The crude metabolites inhibited the growth of bacterial pathogens including Staphylococcus aureus, Staphylococcus epidermidis, Enterococcus faecalis, Escherichia coli, Pseudomonas aeroginosa, $K$. pnuemoniae, Proteus mirabilis and negative inhibition towards the fungal pathogens Candida albicans and Aspergillus sp. A narrow varying zone was observed around the wells loaded with concentration of samples $40 \mu \mathrm{l}$ and after 24 to 48 hours of incubation (Figure 9).

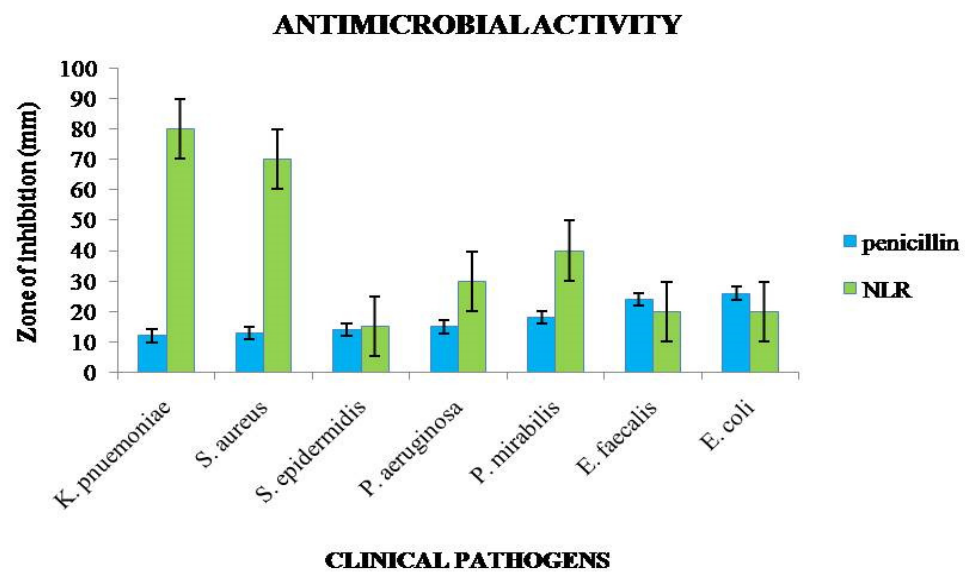

Figure 9. Antimicrobial activity of CMP from Xylaria arbuscula (NLR)

\section{Discussion}

The present work reported on endophytic fungi Xylaria arbuscula, Paraphoma radicina, Phomopsis phaseoli, Sordaria fimicola, Aspergillus amstelodami, Diaporthe eucalyptorum from Blumea axillaris. In this investigation, six potential fungal isolates were screened and characterized by microscopic features such as hyphal and spore arrangements. Morphological features in endophytes are clearly identified and subjected to sequencing using the primers ITS1 and ITS4; as molecular identification and the sequences of organisms represented in the NCBI database gene bank using BLAST search to generate a phylogenetic tree. Through antagonism; non pathogenic strain NLR Xylaria arbuscula can be taken into future studies. (Rogers, 1984) 
reported that $X$. arbuscula have high or less gregarious stroma, sterile stromal apex and smooth ectostromata. And their stromal surfaces in young stage are pale yellow colour, in mature condition becoming black. Likewise, Xylaria arbuscula strain from Blumea root also comparable to it. Media optimisation for Xylaria arbuscula showed better results in Malt extract broth exhibiting highest biomass and crude metabolite production of $10.95 \mathrm{~g} / \mathrm{L}$ and $5.98 \mathrm{UL} / \mathrm{g}$ respectively.

Secondary metabolites from $X$ ylaria proved to be valuable drugs for human health worldwide (Ramesh et al., 2015). Reports on endophytic Xylaria have mutualism and not latent saprophytic and Xylaria have actively produce secondary metabolites in its in vitro studies and Such metabolites include antifungal, antibiotic compounds (Brunner and Petrini, 1992; Petrini et al., 1995 and shows the antagonism in the growth of a wide range of plant and human pathogenic bacteria and fungi (Strobel et al., 2001). Likewise, in these previous studies pertaining Xylaria family, Xylaria arbuscula manifested significant antagonism and antibacterial activity. Xylariaceous endophytes are being recognized as a source of novel metabolic products for use in pharma, agriculture, and industrial biofuel applications (Wu et al., 2017). Besides Xylaria, only some genera of the Xylariaceae novel secondary metabolites have been described in the past 3 years. Those included Nemania, Rosellinia, and Dematophora, the latter of which has recently been resurrected and emended (Wittstein et al., 2020). Cytochalasans are distributed over many genera within Xylariales, including the large families Xylariaceae and Hypoxylaceae. In 2019, the known 19,20-epoxycytochalasin C (6) and D, as well as 18-deoxy-19,20- epoxycytochalasin C were described from an endophytic Nemania sp. (Kumarihamy et al., 2019). A recent example is Xylaria cf. curta, which was isolated as an endophyte from potato stem tissue. Cultures of this fungus yielded numerous interesting metabolites after extensive preparative work. Among those, the curtachalasins (e.g. 9-10) as well as xylarichalasin A (11) have to be highlighted due to their unprecedented core structures: the former harbor a tetracyclic backbone (Wang et al., 2018; Wang et al., 2019), while in the latter, a highly complex hexacyclic structure was found (Wang et al., 2019). A novel abietane diterpenoid named hydroxydecandrin G (22) isolated from an endophytic Xylaria sp. (Han et al., 2019) exhibited very strong shoot elongation inhibition against wheat (IC50 of $23.6 \mu \mathrm{M})$, which was stronger than that of the reference glyphosate $(42.3 \mu \mathrm{M})$, suggesting potential as a natural herbicide.

Free radical scavenging activity is accurate and widely used method to stumble on the antioxidant potential. Endophytes have antioxidant properties where it is worn for pharma purposes. Studies reported that certain species of mushroom have an ability to act as an antioxidant (Hung and Nhi, 2012). The 55.67\% DPPH radical scavenging activity of $X$. papulis is greater that the percentage radical scavenging activity from those in Lentinus edodes (53.90\%) (Boonsong et al., 2016), Tricholoma portentosum (Fr.) (30.40\%) (Ferreira et al., 2007), Auricularia polytricha (21.10\%) (Hung and Nhi, 2012) and Polyporus squamosus (43.30\%) (Keles et al., 2011). Antibacterial activity of the Xylaria arbuscula was carried out in these pathogens $S$. aureus, $S$. epidermidis, E. faecalis, E. coli, P. aeroginosa, K. pnuemoniae and Proteus mirabilis. Among these pathogens strain, $X$. arbuscula showed the highest antibacterial activity in the $K$. pnuemoniae and least in $S$. epidermidis.

Endophytic fungi are a sociable and unswerving source of unique natural amalgams with a high level of biodiversity and also yield many pharmaceutical significant compounds, and currently attracting the attention of scientific researchers globally. The symbiotic association of host-endophyte relationships at the molecular and genetic levels will aid to enhance secondary metabolite production. The search of novel niches useful in finding endophytic microorganisms can be a dynamic area for future investigations. There are a number of bioactive compounds, such as camptothecin, diosgenin, hypericin, paclitaxel, podophyllotoxin, and vinblastine, which have been commercially produced by different endophytic fungi present in respective plants and they are of both agricultural as well pharmaceutical importance (Joseph and Priya, 2011). These compounds are analogs of various types of phytohormones, essential oils etc. isolated from various endophytes (Molina et al., 2012; Nicoletti and Fiorentino, 2015). Moreover, the previous researches in our laboratory on endophytic fungi exhibited antimicrobial, antioxidant, anti- angiogenic and anti- cancer activities from different crude and purified extracts of C. australiensis, Alternaria citrimacularis, Al. alternata and Cladosporium cladosporides (Mani et al., 2015a, b; Mani et al., 2021). Our first report will significantly 
contribute a vital role in pharma industries in the development of antioxidant and anti-cancer therapeutics. Furthermore, the multi-omic analyses that combine information from multiple data sources, such as metabolomes, proteomes and transcriptomes will provide a deep revelation into the purposeful changes of the internal microbiome. Correspondingly, the computational tools to analyze microbiome time-series data are another area that manifest tremendous growth. These techniques could model the inter-individual variability, while automatically capturing commonalities at appropriate levels in the ecosystems (Gerber, 2014).

\section{Conclusions}

According to the present study, the medicinal plant Blumea axillaris serves as a better host for many endophytic fungi and the isolated endophytic fungi exhibited its maximized antagonistic activity. The isolated strains evinced their fungal nature upon morphological and molecular identification. In this current investigation, the fungus Xylaria arbuscula manifested the highest antagonistic activity among the isolated endophytic fungal isolates against most of the tested pathogens. Thus, the bioactive metabolites were enhanced through optimization process from the fungus $X$. arbuscula and the crude metabolites extract revealed their highest antioxidant and antimicrobial activities. Further, there is a need to study their secondary metabolite screening, characterization and its biological activity, which would contribute for the large-scale production of these biologically active components for use in the pharmaceutical industry.

\section{Authors' Contributions}

Designed and wrote the main manuscript text: NL, KP, VMM; Experiments performed by: NL, NS; Plant sample collected by: NL, RD; Reagents/materials/analysis tools provided by: KP; The final draft edited by: NL, KP, VMM; All authors read and approved the final manuscript.

\section{Acknowledgements}

Author Lavanya Nehru is thankful to the Department of Science and Technology ((DST- PURSE (PHASE-II)) Government of India), Bharathiar University for the Financial Support throughout the project, Grant no: BU/DST PURSE (II) APPOINTMENT/3 \& 07.12.2017.

\section{Conflict of Interests}

The authors declare that there are no conflicts of interest related to this article.

\section{References}

Barry AL, Garcia F, Thrupp LD (1970). An improved single-disk method for testing the antibiotic susceptibility of rapidly-growing pathogens. American Journal of Clinical Pathology 53:149-158. https://doi.org/10.1093/ajcp/53.2.149

Bauer AW, Kirby WM, Sherris JC, Turck M (1966). Antibiotic susceptibility testing by a standardized single disk method. American Journal of Clinical Pathology 45:493-496. 
Bérdy J (2005). Bioactive microbial metabolites - A personal view. Review. The Journal of Antibiotics 58(1):1-26. https://doi.org/10.1038/ja.2005.1

Berdy J (2012). Thoughts and facts about antibiotics: where we are now and we are heading. The Journal of Antibiotics 65:385-395. https://doi.org/10.1038/ja.2012.27

Boonsong S, Klaypradit W, Wilaipun P (2016). Antioxidant activities of extracts from five edible mushrooms using different extractants. Agriculture and Natural Resources 59-97. http://dx.doi.org/10.1016/j.anres.2015.07.002

Brunner F, Petrini O (1992). Taxonomy of some Xylaria species and xylariaceous endophytes by isozyme electrophoresis. Mycological Research 96:723-733. https://doi.org/10.1016/s0953-7562(09)80440-1

Bukelskienè V, Baltriukienė D, Repečkienè J (2006). Study of health risks associated with Aspergillus amstelodami and its mycotoxic effects. Ekologija 3:42-47.

Dereeper A, Guignon V, Blanc G, Audic S, Buffet S, Chevenet F, ... Gascuel O (2008). Phylogeny. fr: robust phylogenetic analysis for the non-specialist. Nucleic Acids Research 1:36. https://doi.org/10.1093/nar $/ \mathrm{gkn} 180$

Doss RP, Welty RE (1995). A polymerase chain reaction-based procedure for detection of Acremonium coenophialum in tall fescue. Phytopathology 85:913-917. https://doi.org/10.1094/Phyto-85-913

Edgar RC (2004). MUSCLE: multiple sequence alignment with high accuracy and high throughput. Nucleic Acids Research 32(5):1792-1797. https://doi.org/10.1093/nar/gkh340

Fathima BS, Balakrishnan RM (2014). Biosynthesis and optimization of silver nanoparticles by endophytic fungus Fusarium solani. Materials Letters 132:428-431. https://doi.org/10.1016/j.matlet.2014.06.143

Ferreira I, Baptista P, Vilas-Boas M, Barros L (2007). Free-radical scavenging capacity and reducing power of wild edible mushrooms from northeast Portugal: Individual cap and stipe activity. Food Chemistry 1511-1516. http://dx.doi.org/10.1016/j.foodchem.2005.11.043

Fokkema NJ (1978). Fungal antagonism in the phylosphere. Annals of Applied Biology 89:115-117. http://dx.doi.org/10.2298/ABS1003611Z

Gade AK, Bonde P, Ingle AP, Marcato PD, Duran N, Rai MK (2008). Exploitation of Aspergillus niger for synthesis of silver nanoparticles. Journal of Biobased Materials and Bioenergy 2(3):243-247. http://dx.doi.org/10.1166/jbmb.2008.401

Gerber GK (2014). The dynamic microbiome. FEBS Letters 588:4131-4139. https://doi.org/10.1016/j.febslet.2014.02.037

Gond SK, Mishra A, Sharma VK, Verma SK, Kumar J, Kharwar RN, Kumar A (2012). Diversity and antimicrobial activity of endophytic fungi isolated from Nyctanthes arbor-tristis, a well-known medicinal plant of India. Mycoscience 53(2):113-121.

Gond SK, Verma VC, Kumar A, Kumar V, Kharwar RN (2007). Study of endophytic fungal communities from different parts of Aeglemarmelos correae (Rutaceae) from Varanasi (India). World Journal of Microbiology and Biotechnology 23:1371-1375.

Han WB, Zhai YJ, Gao Y, Zhou HY, Xiao J, Pescitelli G, Gao JM (2019). Cytochalasins and an abietane-type diterpenoid with allelopathic activities from the endophytic fungus Xylaria species. Journal of Agricultural and Food Chemistry 67:3643-3650. https://doi.org/10.1021/acs.jafc.9b00273

Hung PV, Nhi NNY (2012). Nutritional composition and antioxidant capacity of several edible mushrooms grown in the Southern Vietnam. International Food Research Journal 19(2):611-615. https://www.researchgate.net/publication/267036593

Ivanová H (2015). Sordaria fimicola (Ascomycota, Sordariales) on Acer palmatum. Folia Oecologica 42:67-71.

Johan C, Janse van Rensburg Sandra C, Lamprecht Johannes Z, Groenewald Lisa A, Castlebury, Pedro W Crous (2006). Characterisation of Phomopsis spp. associated with die-back of rooibos (Aspalathus linearis) in South Africa. Studies in Mycology 55:65-74. https://doi.org/10.3114/sim.55.1.65

Joseph B, Priya RM (2011). Bioactive compounds from endophytes and their potential in pharmaceutical effect: a review. American Journal of Biochemistry and Molecular Biology 1:291-309. https://dx.doi.org/10.3923/ajbmb.2011.291.309

Keles A, Koca I, Genccelep H (2011). Antioxidant properties of wild edible mushrooms. Journal of Food Processing Technology 2(6):1-6. https://doi.org/10.4172/2157-7110.1000130

Kumarihamy M, Ferreira D, Croom EM Jr, Sahu R, Tekwani BL, Duke SO, ... Nanayakkara NP (2019). Antiplasmodial and cytotoxic cytochalasins from an endophytic fungus, Nemania sp. UM10M, isolated froma diseased Torreya taxifolia leaf. Molecules 24:777. https://doi.org/10.3390/molecules24040777 
Lacap DC, Hyde KD, Liew EC (2003). An evaluation of the fungal 'morphotype' concept based on ribosomal DNA sequences. Fungal Diversity 12:53-66. http://dx.doi.org/10.3897/mycokeys.32.23670

Majumdar MK, Majumdar SK (1965). Effects of minerals on neomycin production by Streptomyces fradiae. Journal of Applied Microbiology 13:190-193. https://dx.doi.org/10.1128\%2Faac.8.4.391

Mani VM, Priya MS, Dhayalini S, Preethi K (2015b). Antioxidant and antimicrobial evaluation of bioactive pigment from Fusarium sp isolated from stressed environment. International Journal of Current Microbiology and Applied Sciences 4(6): 1147-1158.

Mani VM, Soundari AJPG, Balasubramanian B, Park S, Issara U, Preethi K, Liu W-C (2021). Evaluation of dimer of epicatechin from an endophytic fungus Curvularia australiensis FC2AP on Acute toxicity levels, antiinflammatory and anti-cervical cancer activity in animal models. Molecules 26(3):654. https://doi.org/10.3390/molecules26030654

Mani VM, Soundari APG, Ashokraj S, Priyadarisini VB (2017). Molecular and functional characterization of metabolites from terrestrial Streptomyces hygroscopicus AVS7 isolated from Western Ghats, India. Journal of Pure and Applied Microbiology 11(4):1823-1831.

Mani VM, Soundari APG, Karthiyaini D, Preethi K (2015a). Bioprospecting for endophytic fungi and their metabolites from medicinal tree Aegle marmelos in Western Ghats, India. Mycobiology 43(3):303-310. https://dx.doi.org/10.5941\%2FMYCO.2015.43.3.303

Mani VM, Soundari APG, Tamilarasi S (2018). Determination of in vitro cytotoxicity and anti- angiogenesis for a bioactive compound from Aspergillus terreus FC36AY1 isolated from Aeglemarmelosaround Western Ghats, India. In Tech Open- Book:Medicinal Chemistry, pp 13- 28.

Molina G, Pimentel MR, Bertucci TCP, Pastore GM (2012). Application of fungal endophytes in biotechnological processes. Chemical Engineering Transactions 27:289-294. https://doi.org/10.7324/JAPS.2012.2807

Moslemi A, Ades PK, Groom T, Crous PW, Nicolas ME, Taylor PWJ (2016). Pharaphoma crown rot of pyrethrum (Tanacetum cinerariifolium). Plant Disease Journal (12):2363-2369. https://doi.org/10.1094/PDIS-05-160628-RE

Naik MK, Hiremath PC, Hegde RK (1988). Physiological and nutritional studies on C. gloeosporioides, a causal agent of anthracnose of beetlevine. Mysore Journal of Agricultural Science 22:471-474.

Newman DJ, Cragg GM (2014). Marine-sourced anti-cancer and cancer pain control agents in clinical and late pre-clinical development. Marine Drugs 12:255-278. https://doi.org/10.3390/md12010255

Nicoletti R, and Fiorentino A (2015). Plant bioactive metabolites and drugs produced by endophytic fungi of Spermatophyta. Agriculture 5:918-970. https://doi.org/10.3390/agriculture5040918

Petrini O, Petrini LE, Rodrigues K (1995). Xylariaceaous endo-phytes: an exercise in biodiversity. Fitopatologica Brasiliensis 20:531-539.

Preethi K, Mani VM, Lavanya N (2021). Endophytic fungi: a potential source of bioactive compounds for commercial and therapeutic applications. In: Patil RH, Maheshwari VL (Eds). Book: Endophytes. Springer, Singapore. https://doi.org/10.1007/978-981-15-9371-0_12

Ramesh V, Santosh K, Anand TD., Shanmugaiah V, Kotamraju S, Karunakaran C, Rajendran A (2015). Novel bioactive wild medicinal mushroom-Xylaria sp. R006 (Ascomycetes) against multidrug resistant human bacterial pathogens and human cancer cell lines. International Journal of Medicinal Mushrooms 17:1005-1017. https://doi.org/10.1615/IntJMedMushrooms.v17.i10.100

Ripa FA, Nikkon F, Zaman S, Khondkar P (2009). Optimal conditions for antimicrobial metabolites production from a new Streptomyces sp. RUPA-08PR isolated from Bangladeshi soil. Mycobiology 37(3):211-214. https://doi.org/10.4489/MYCO.2009.37.3.211

Rodriguez RJ, Woodward CJ Redman RS (2012). Fungal influence on plant tolerance to stress. In: Blackwell W (Ed). Biocomplexity of Plant-Fungal Interactions. Oxford, UK pp 155-163.

Rogers JD (1984). Xylaria acuta, Xylaria cornu-damae, and Xylaria mali in continental United States. Mycologia 76:2233 https://doi.org/10.2307/3792832

Rogers JD, Samuels GS (1986). Ascomycetes of New Zealand. 8. Xylaria. New Zealand Journal of Botany 24:615-650. https://doi.org/10.1080/0028825X.1986.10409947

Saikkonen K, Saari S, Helander M (2010). Defensive mutualism between plants and endophyticfungi? Fungal Diversity 41:101-113. http://dx.doi.org/10.1007/s13225-010-0023-7

Schulz B, Boyle C (2005). The endophytic continuum. Mycological Research 109:661-686. https://doi.org/10.1017/S095375620500273X 
Selim KA, El-Beih AA, AbdEl RTM, Diwany AI (2012). Biology of endophytic fungi. Current Research in Environmental \& Applied Mycology 2:31-82. https://doi.org/10.5943/cream/2/1/3

Senthilkumar A, Kannathasan K, Venkatesalu V (2008). Chemical constituents and larvicidal properties of the essential oil of Blumea mollis (D. Don) Merr. against Culex quinquefasciatus. Parasitology Research 103(4):959-962. https://doi.org/10.1007/s00436-008-1085-2

Singh D, Rathod V, Singh AK, Joshi R, Nagaratna H, Azmathunnisa, Avinash B (2015). Antibacterial activity and phytochemical analysis of the crude extracts of endophytic fungus, Alternaria sp. from the medicinal plant Euphorbia hirta (L). International Journal of Green Chemistry and Bioprocess 5:14-20.

Singh LS, Mazumder S, Bora TC (2009). Optimisation of process parameters for growth and bioactive metabolite produced by a salt-tolerant and alkaliphilic actinomycete, Streptomyces tanashiensis strain A2D. Journal of Medical Mycology 19:225-233.

Sivanandhan S, Ganesan P, Jackson A, Darvin S, Paulraj MG, Ignacimuthu S (2018). Activity of some medicinal plants against phytopathogenic fungi. International Journal of Scientific Research in Biological Sciences 5(5):124-137. https://doi.org/10.26438/ijsrbs/v5i5.124137

Sreelekha KP, Ajeesh Krishna TP, Adarsh Krishna TP, Deepa PE, Udayan D, Juliet S, ... Ravindran R (2017). Pharmacochemical characterization of leaves of Blumea mollis (D. Don) merr. from Western Ghats of Wayanad region of Kerala, India. Journal of Pharmacognosy and Phytochemistry 6(4):319-323.

Strobel G, Daisy B (2003). Bioprospecting for microbial endophytes and their natural products. Microbiological and Molecular Biology Reviews 67:491-502. https://dx.doi.org/10.1128\%2FMMBR.67.4.491-502.2003

Strobel GA, Dirkse E, Sears J, Markworth C (2001). Volatile antimicrobials from Muscodor albus, a novel endophytic fungus. Microbiology 147:2943-2950. https://doi.org/10.1099/00221287-147-11-2943

Talavera G, Castresana J (2007). Improvement of phylogenies after removing divergent and ambiguously aligned blocks from protein sequence alignments. Systematic Biology 56:564-577. https://doi.org/10.1080/10635150701472164

Uecker FA (1988). A world list of Phomopsis names with notes on nomenclature, morphology and biology. Mycologia Memoir 13:1-231.

Vellingiri MM, Arockiam Jeyasundar PGS, Venkatesan BP, Balakrishnan B, Liu W (2021). Statistical optimization of parameters for enhanced bioactive metabolites produced by Streptomyces hygroscopicus AVS7. Arabian Journal of Science and Engineering 46:5345-5360. https://doi.org/10.1007/s13369-020-05116-y

Vigneshwari A, Rakk D, Németh A, Kocsubé S, Kiss N, Csupor D, Papp T, ... Szekeres A (2019). Host metabolite producing endophytic fungi isolated from Hypericum perforatum. Plos One 14(5):e0217060. https://doi.org/10.1371/journal.pone.0217060

Walsh CT, Fischbach MA (2010). Natural products version 2.0: connecting genes to molecules. Journal of American Chemical Society 132:2469-2493. https://doi.org/10.1021/ja909118a

Wang WX, Lei X, Ai HL, Bai X, Li J, He J, ... Liu JK (2019). Cytochalasans from the endophytic fungus Xylaria cf. curta with resistance reversal activity against fluconazole-resistant Candida albicans. Organic Letters 21:1108-1111. https://doi.org/10.1021/acs.orglett.9b00015

Wang WX, Lei X, Yang YL, Li ZH, Ai HL, Li J, ... Liu JK (2019). Xylarichalasin A, a halogenated hexacyclic cytochalasan from the fungus Xylaria cf. curta. Organic Letters 21:6957-6960. https://doi.org/10.1021/acs.orglett.9b02552

Wang WX, Li ZH, Feng T, Li J, Sun H, Huang R, ... Liu JK (2018). Curtachalasins A and B, two cytochalasans with a tetracyclic skeleton from the endophytic fungus Xylaria curta E10. Organic Letters 20:7758-7761. https://doi.org/10.1021/acs.orglett.8b03110

Wittstein K, Cordsmeier A, Lambert C, Wendt L, Sir EB, Weber J, ... Stadler M (2020). Identification of Rosellinia species as producers of cyclodepsipeptide PF1022 A and resurrection of the genus Dematophora as inferred from polythetic taxonomy. Study of Mycology 96:1-16. https://doi.org/10.1016/j.simyco.2020.01.001

Wu W, Davis RW, Tran-Gyamfi MB, Kuo A, LaButti K, Mihalcheva S, ... Gladden JM (2017). Characterization of four endophytic fungi as potential consolidated biosprocessing hosts for conversion of lignocellulose into advanced biofuels. Bioenergy and Biofuels 101:2603-2618. https://doi.org/10.1007/s00253-017-8091-1

Xu L, Zhou L, Zhao J, Jiang W (2008). Recent studies on the antimicrobial compounds produced by plant endophytic fungi. Natural Product Research and Development 20:731-740.

Yildirim A, Mavi A, Kara AA (2001). Determination of antioxidant and antimicrobial activities of Rumex crispus L. extracts. Journal of Agriculture and Food Chemistry 9:4083-4089. https://doi.org/10.1021/jf0103572 
OPEN ACCESS The journal offers free, immediate, and unrestricted access to peer-reviewed research and scholarly work. Users are allowed to read, download, copy, distribute, print, search, or link to the full texts of the articles, or use them for any other lawful purpose, without asking prior permission from the publisher or the author.

(C) (9)

License - Articles published in Notulae Scientia Biologicae are Open-Access, distributed under the terms and conditions of the Creative Commons Attribution (CC BY 4.0) License.

( $)$ Articles by the authors; SHST, Cluj-Napoca, Romania. The journal allows the author(s) to hold the copyright/to retain publishing rights without restriction. 